\title{
Oxidative Stress and Its Association with COVID-19: A Narrative Review
}

\author{
Hardi Rafat Baqi \\ Medical Laboratory Science \\ Technical College of Applied Sciences Research Center \\ Sulaimani Polytechnic University \\ Sulaimani, Iraq \\ hardi.baqi@spu.edu.iq
}

\author{
Halgord Ali M. Farag \\ Nursing Department \\ Technical College of Health | Research Center \\ Sulaimani Polytechnic University \\ Sulaimani, Iraq \\ halgord.farag@spu.edu.iq
}

\author{
Abdel Hamid H. El Bilbeisi \\ Clinical Nutrition Department \\ Faculty of Pharmacy \\ Al Azhar University of Gaza \\ Gaza, Palestine \\ abedazhot@gmail.com
}

\author{
Rafee Habib Askandar \\ Nursing Department \\ Technical College of Health \\ Sulaimani Polytechnic University \\ Sulaimani, Iraq \\ rafee.askandar@spu.edu.iq
}

Amany M. El Afifi

Clinical Pharmacy Department

Faculty of Pharmacy

Al Azhar University of Gaza

Gaza, Palestine

amany.elafifi95@gmail.com

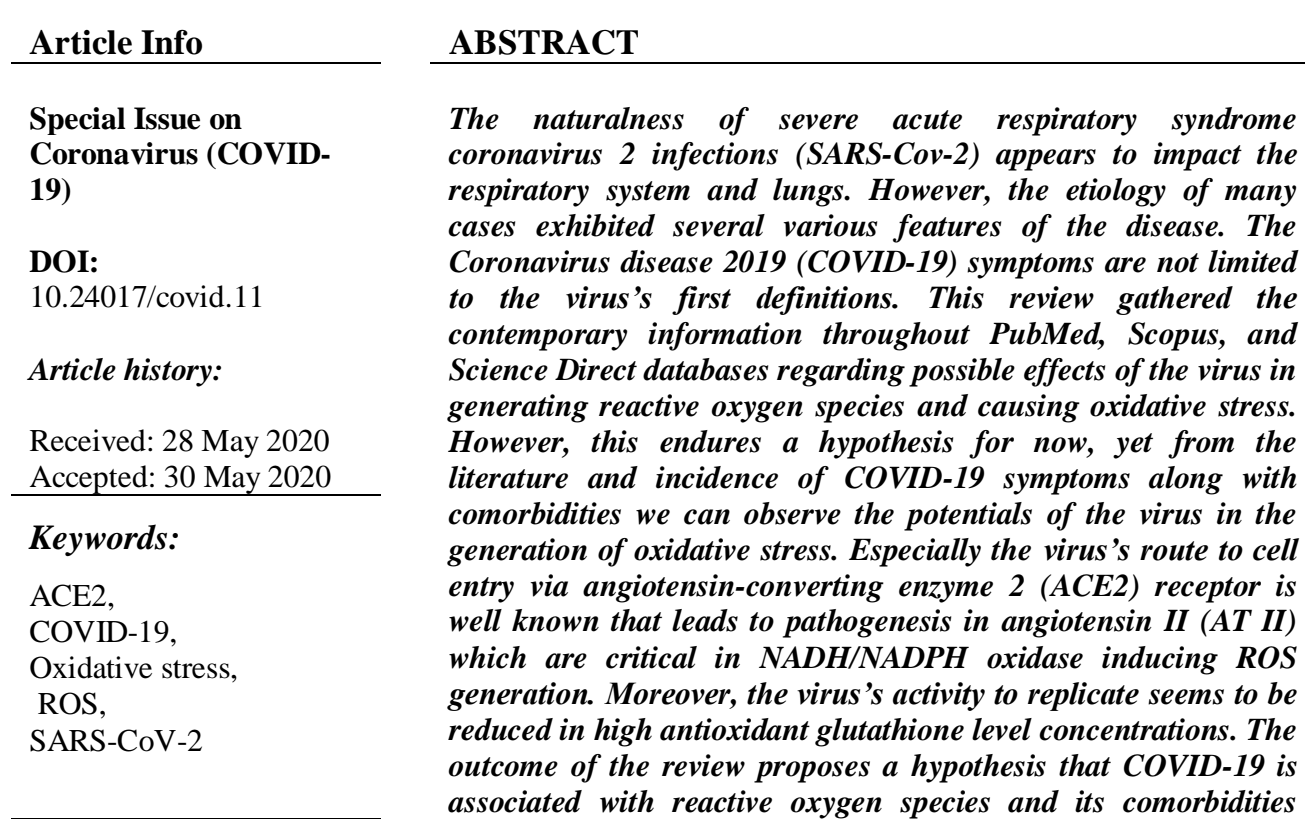


mostly joined with oxidative stress including hypertension, cardiovascular, thrombosis, obesity, and diabetes besides of chronic obstructive pulmonary disease and asthma.

\section{INTRODUCTION}

The emerging pandemic with severe acute respiratory syndrome coronavirus 2 (SARS-CoV2) initiated with symptomatic individuals of respiratory infections in Wuhan, China's Hubei province in mid-December 2019. At first, the exact causes of the new outbreak were unknown, so the cases were classified as "pneumonia of unknown etiology." After intensive investigations, the etiology of the disease linked to the coronavirus $(\mathrm{CoV})$ family's novel virus [1]. The new virus is a non-segmented enveloped RNA virus that comes from widely dispersed in animals and humans subfamily of viruses namely sarbecovirus, orthocoronavirinae [2],[3]. The single-stranded virus has a diameter of about $65-125 \mathrm{~nm}$ with a crown-like outer surface. It comes as a novel $\beta$-coronavirus following earlier identifications of MERS-CoV and SARS-CoV which assured outbreaks mostly in China, Guandong, and Saudi Arabia with symptoms of strong respiratory tract infections and pulmonary failure. The origin of the new novel coronavirus is doubted to be from bats. Researchers found $96.2 \%$ similarity in genome sequencing between the bat CoV RaTG13 and SARS-CoV-2 [4],[5]. The new 2019-nCoV adopts the same entry mechanism as its ancestor SARS-CoV, which is exploiting the receptor angiotensin-converting enzyme II (ACE2) [6]. The mechanism of the cellular entry relies on the tethering of the subsequent $S$ protein prepared by the cellular proteases and spike (S) protein to the receptor [7]. Although the virus's path of entry is through the lungs, but the virus's ACE2 receptor is broadly expressed in the human body, especially in the heart, gastrointestinal system, kidney, and the lung's type II alveolar [8], which makes it feasible for the virus to do its damage in cells other than of respiratory system.

\section{Oxidative stress (OS):}

The OS is an imbalance in prooxidant-antioxidant level gratifying the prooxidants that costs cell to die [9]. During the normal physiological functions of cells, reactive oxygen species (ROS) are essential to maintain smooth biological function, however, the role of ROS is firmly coordinated via redox regulation, redox sensing, and redox signaling [10]. During abnormal physiological conditions, the OS occurs due to the uncontrolled ROS production in which redox signaling is disrupted and causes molecular damage [11]. Although, the new redox signaling pathways redefined OS with two new mechanisms including disruption of thiol redox circuits and macromolecular damage leading to irregular signaling of the cells and non-functioning redox control [12],[13]. This disruption in redox circuits by specific reactions with thiol elements that are sensitive to redox reactions change the electron transfer or interrupt the gating mechanism that has a crucial role in physiopathology and physiology [13]. OS induces protein oxidations and deregulates cell signals causing impairment of many important processes in vascular function, activation of immune cells, remodeling of cardiovascular, renal dysfunction and the sympathetic nervous system excitation such as inflammation, apoptosis, proliferation, migration, and fibrosis [14]. Generation of high ROS levels due to toxins, pollutants, and airways viral infections are linked with OS that causes damage to the cells. The respiratory system's viral infections are linked with the production of cytokine, cellular damage, inflammation and some other pathophysiological processes that have potential links with OS or redox imbalance. High levels of ROS with deprived antioxidant mechanisms are of great importance for viruses to replicate, and cause disease 
[15]. There is a certain association between OS and inflammation [16]. Many viruses that infect the respiratory system induce an increase in ROS formation in response to high levels of infected cells. Besides, viral infections act on antioxidant mechanisms making an imbalance status between oxidative-antioxidants that result in cell damage because of the OS. The mechanisms by which ROS induce the function of the cell are through post-translational modification including phosphorylation, and oxidation (nitrosylation, sulfenylation, glutathionylation, and carbomylation) [17],[18],[19]. The proteins that are sensitive toward the oxidation effect of the ROS are receptors, ion transporters, signaling molecules, transcription factors, matrix metalloproteases (MMP) and cytoskeletal structural proteins in which all participate in the regulation of vascular, cardiac, and renal function [19],[20]. In normal balanced status of oxidative-antioxidants, during exposure to pro-oxidants, the (Nrf2) a nuclear factor erythroid-2-related factor 2 is activated and an antioxidant response regulates the status, but in respiratory viral infections the Nrf2 factor is inhibited and (NF-kB) a nuclear factor kappa-light-chain-enhancer of activated B cells signaling is activated that causes further inflammation and cell damages due to OS [21]. Cell proliferation is induced via oxidative stress, apoptosis, inflammation and hypertrophy through initiation of chain redox reactions. The activity of free radicals with other ROS molecules can oxidize various molecules. Protein oxidations and lipid oxidation results in damages of vascular smooth muscle cells (VSMCs), endothelial cells, myocardial cells, and by changing the expression of redox genes, an intracellular calcium overload, and fragmentation of DNA [22].

\section{SARS-Cov-2 entry mechanism to the cell}

The length of SARS-CoV-2 strains showed to have $29.2 \mathrm{~kb}$. The sample isolates were taken from COVID-19 patients with pneumonia from Wuhan's seafood market [23]. The structure of SARS-CoV-2 is comprised of many accessory proteins with four main structural proteins that are small envelope (E) glycoprotein, nucleocapsid (N) protein, spike (S) glycoprotein, and membrane (M) glycoprotein, [24]. On the surface of the virus, the $\mathrm{S}$ spike proteins with molecular weights of about $150 \mathrm{kDa}$ are located. The $\mathrm{S}$ protein binds the virus with host cells by forming homotrimers sticking on the top of the virus which accelerates the binding between the ACE2 enzymes in the cells of the lower respiratory tract with the envelope virus. The glycoprotein from the surface of the virus is cleaving into two subunits S1 and S2 by the activity of protease enzymes from the host cell. The S1 part is responsible to the cellular tropism for making of a binding domain to the receptor and determination of host-virus range. Whereas, the mediation to the fusion of the virus in transmitting host cells is done by S2 part [4],[25],[26]. The ACE2 receptor is highly expressed in lung's type II alveolar cells (AT2), stratified epithelial cells, and upper esophagus with cells from the colon and ileum, myocardial, kidney's proximal tubule, cholangiocytes, and proximal urothelial cells [27]. The abundance of ACE2 receiver in other than respiratory cells expand the symptomatic features of COVID-19 to include problems such as cardiovascular, digestive tract, and kidneys [28].

\section{NADH/NADPH Oxidase:}

The majority of vasculature's ROS are come from NADH/NADPH oxidase, these are nonphagocytic oxidases that include (Nox1, Nox2, Nox4, Nox 5 (humans) and Nox1, Nox2, Nox4 (rodents)) [29],[30]. Many pathways mediate NADH/ NADPH oxidase induced ROS production [31], one of the main sources is because of AT II [32]. The ACE2 receptor generates angiotensin 1,7 (AT 1,7) from angiotensin II (AT II) that balances the ACE effect in which generates AT II from AT I [33]. AT II with ET-1 are among many vasoactive factors in circulation that are important in pathophysiology hypertension [34],[35]. High ROS levels in vascular as an effect of ATII, ET-1with some other vasoactive peptides activates the $\mathrm{Ca}^{2+}$ channels that piles up the $\mathrm{Ca}^{2+}$ activating Nox sensitive to $\mathrm{Ca}^{2+}$, this process consequently leads to amplification of redox signaling and damages the epithelium cell [36]. 


\section{LITERATURE REVIEW}

\subsection{The association of OS markers with some viral infection}

The association of OS markers with some viral infection severities such as hepatitis $\mathrm{C}$ (HCV) virus is obvious, yet regarding the SARS-CoV virus the clinical data is finite, even though some lines of evidence propose that the ROS overproduction along with depletion of antioxidant functions have a great importance in the pathogenesis of SARS-CoV infections accompanied by the severity and development of the respiratory diseases. Animal studies of SARS models exhibited an increase in levels of ROS with distress in antioxidant levels in the time of infection with SARS-CoV [37]. The lung injury severities of infected SARS-CoV patients are speculated to be in association with transcription factors including $\mathrm{NF}_{-\mathrm{k}} \mathrm{B}$ that are activated as a result of OS coupling with innate immunity, worsen the pro-inflammatory response of the host cell [38]. A viral protease enzyme $3 C^{\text {pro }}$ of SARS-CoV is entangled in apoptosis of cell by increasing the generation of ROS in HL-CZ cells. The viral protease enzyme activates a reporter gene that is $\mathrm{NF}_{-\mathrm{k}} \mathrm{B}$ factor-dependent that linked with $\mathrm{ROS}$ generation in $\mathrm{HL}-\mathrm{CZ}$ cells. The $\mathrm{NF}_{-\mathrm{k}} \mathrm{B}$ factor also appears in other apoptosis and proinflammatory genes, this suggests that the viral protease plays a central role in SARS-CoV pathophysiology [39]. Moreover, 3a protein of SARS-COV is linked with mitochondrial cell death pathways. The mechanism of this protease in Huh7 cells is depended on the activation of p38 mitogen-activated protein kinase (MAPK) and involves high levels of p53 protein expression and Bax oligomerization. MAPK are activated due to oxidative stress, DNA damage, viral infections and carcinogenic stimulations [40]. The active phosphorylated MAPK form has been found in infected SARS CoV cells [15]. The pathogens, including viral such as SARS CoV can amplify the inflammatory response of the host cells in a reaction to oxidative stress induced on $\mathrm{NF}_{-\mathrm{k}} \mathrm{B}$, this finally causes lung injury [41]. The bond between OS, pathogenesis and inflammation of SARS-CoV is proved by regulation of mitochondrial genes and genes responsible for OS in peripheral blood mononuclear cells (PBMC) in recovering SARS CoV patients. The sensitive genes to OS such as, FTH1, PRDX1, and FOS exhibited a striking increase in their expression, furthermore, IFRDI, IL-IB, and some other genes that are associated with stress response protein DNAJBI all overexpressed in PBMC of SARS-CoV infected patients [42]. In the consequence of OS with deprived antioxidant mechanisms aging process occurs [43],[44], in aged mice, SARS CoV induced more severely than the younger mice. The expression of the virus in the proinflammatory medium is higher as seen in older mice. This result suggests the age-related OS with weak antioxidant system disturbs the balance and rises the ROS. Consequently, other than the adaptive immune function that is affected by the ageing process, but the whole host cell becomes a proinflammatory environment. However, an immune response of host cells with differential expression of inflammation-associated genes in which NF-kB played a central role, was stronger in younger macaques [45].

\subsection{OS effect on cardiac function}

The key signaling molecules for mediation of the regulation and homeostasis of intracellular calcium that is critical for the maintenance and triggering of the vasoconstriction and cardiac contractions are ROS in which signal the vasoactive agents like ATII, endothelin-1 (ET-1), prostanoids and aldosterone [46],[47],[48],[49]. The vascular and cardiac cell proliferation, hypertrophy, inflammation, and mitigation is controlled by (MAPK) a mitogen-activated protein kinase that all of its three members JNK, ERK1/2, and p38MAPK are activated by ROS [48],[49],[50],[51]. High intracellular levels of $\mathrm{H}_{2} \mathrm{O}_{2}$ promote the phosphorylation of p66Shc that is a major ROS regulator in mitochondria in which involves VEGF which is important in angiogenesis, proliferation, and migration in endothelial cells [52]. According to both clinical and pre-clinical studies, the OS biomarkers in males are confirmed to be higher than females [53], [54], [55]. The highly abundant ROS in the cardiovascular system are $\left(\mathrm{O}_{2}-\right.$ ), $\left(\mathrm{H}_{2} \mathrm{O}_{2}\right),(\mathrm{ONOO}-)$, and (NO) [10],[11],[56]. $\mathrm{O}_{2}-$ is very unstable, impermeable molecule to the cell membrane with a short half-life, $\mathrm{H}_{2} \mathrm{O}_{2}$ with longer half-life is more stable and 
permeable, making it more efficient molecule in signaling [57],[58]. NO which is a prototype endothelial vasodilator is produced by the activity of NOS enzymes [59], [60]. The product of combining the two radicals $\mathrm{O}_{2}-$ and $\mathrm{NO}$ is $\mathrm{ONOO}-$ a short-lived highly unstable molecule with strong oxidation capabilities, if protonated (HOONO) becomes permeable to the cell membrane [61]. The interconversion between $\mathrm{NO}$ and $\mathrm{O}_{2-}$ accompanied by uncontrolled production of $\mathrm{O}_{2}-$ and $\mathrm{H}_{2} \mathrm{O}_{2}$ costs the redox signaling a change in the cell leading to cells and tissue damage as a result of oxidative stress [62].

\subsection{Antioxidant system}

Elevated ROS levels in the cells lead to oxidative stress, some are free radicals possess unpaired electrons that have oxidizing power including superoxide anion $\left(\mathrm{O}_{2}-\right)$, $\mathrm{NO}$, and hydroxyl radical $(\mathrm{OH})$. Others like hydrogen peroxide $\left(\mathrm{H}_{2} \mathrm{O}_{2}\right)$, hypochlorous acid $(\mathrm{HOCl})$, and peroxynitrite (ONOO-) are non-free radicals with oxidation abilities. ROS produced in many cells like vascular smooth muscle cells (VSMCs), endothelial cells, and mononuclear cells by catalyzing activities of many enzymes such as nicotinamide-adenine dinucleotide phosphate (NADPH) oxidase, uncoupled endothelial NO synthase (eNOS), xanthine oxidase, cyclooxygenase, lipoxygenase, glucose oxidase, and mitochondrial electron transport [22]. The enzyme superoxide dismutase (SOD) of three isoforms which are the cytosolic $\mathrm{Cu} / \mathrm{Zn}$ $\mathrm{SOD}$, the extracellular SOD, and mitochondrial Mn-SOD convert $\mathrm{O}_{2}-$ to water through the process of detoxification that also includes catalase, and glutathione peroxidase (GPx) [22],[63]. The homeostasis between the extent of the antioxidant defense and oxidative stress indicates the susceptibility ratio of the vascular cells to the ROS [63].

\subsection{Glutathione}

Glutathione is a tripeptide composed of three amino acids which are cysteine, glycine, and glutamate role as a copious antioxidant that stops the ROS from damaging the cells [64]. Keeping inflated concentrations of a reduced form of the glutathione GSH, in cells is enough to exhibit its importance in jurisdiction of many biological processes including folding of proteins, vitamin $\mathrm{E}$ and $\mathrm{C}$ regeneration, anti-viral actions, cell proliferation regulation, immune response, apoptosis and detoxifying the endogenous and external oxidants [64],[65]. Many studies stressed out the advantages of glutathione on human body acting as an anti-viral, yet, this prominent antioxidant in pathology and clinical applications is misconstrued [66]. The glutathione exhibits antiviral activities in various ways, it's well-known for its role in the inhibition of many types of virus replications, and since the GSH is not limited to one single processes, common sense suggests the possibility of its effectiveness over SARS CoV-2 as well. The ROS/GSH ratio is correlated with the severity of COVID-19, in moderate and severe cases the ROS/GSH ratio was bigger than the milder COVID-19 symptoms. The outcoming results postulate the inactivity of the SARS CoV-2 to replicate in high glutathione levels [66].

\subsection{Evidence supporting bipartite role for oxidative stress and COVID-19}

However the mechanism is not clear, yet the COVID-19 complications in cardiovascular are becoming a prominent threat of the disease other than respiratory diseases [67]. There is evidence that COVID-19 is linked with the incidence of thrombosis [68]. COVID-19 patients with moderate and severe symptoms showed elevated ROS levels accompanied by a decrease in glutathione and a bigger ratio of ROS/GSH, while the patients with milder symptoms kept their glutathione levels [66]. Many studies suggest that ATII pathogenesis increases the production of $\mathrm{O}_{2}$ - in vascular cells, the SARS-CoV-2 interferes ATII while the virus binds to the ACE2 receptor [69],[70],[71]. In COVID-19 patients, neutrophils significantly increase [72], it is well established that neutrophils increase ROS and use for defense mechanism [73]. The ACE2 by generating AT1,7 reduces the ROS effects, maintains functionality of the endothelial cells and through inhibition of the inflammatory response, prevents early atherosclerosis [74],[75]. In an original investigation about comorbidities among 5700 hospitalized patients of COVID-19 in New York City Area, researchers found out 
hypertension was the most common with $56.6 \%$ of the cases, then comes obesity with $41.7 \%$, and diabetes with $33.8 \%$. Only $30.7 \%$ were febrile, among all patients $17.3 \%$ were suffering respiratory issues with 24 breathes per minute and only $27.8 \%$ of the total number of patients needed supplemented oxygen. The rate of chronic obstructive pulmonary disease (COPD) and asthma hospitalized patients were only 5\% and 9\% respectively. From all cases, 553 patients (21\%) died, $320(12.2 \%)$ of patients putted on a mechanical ventilator in which only 38 (3.3\%) discharged alive, $81(3.2 \%)$ of the patients were received therapy for their kidneys [76]. Atherosclerosis starts from endothelial dysfunction leading to cardiovascular diseases. Oxidative stress results in the impairment of the endothelial function and development of cardiovascular diseases through distorting the balance between high reactive oxygen species (ROS) and low NO production in particular superoxide [22]. OS and hypertension are associated in various ways including hypertension induced by endocrine (aldosterone, AT II, deoxycorticosterone acetate DOCA)), stroke-prone SHR (SHRSP), genetic hypertension (spontaneously hypertensive rats (SHR), diet-induced hypertension (zinc, fat, salt), hypertension induced by surgery (two-kidney one clip (2K1C), aortic banding), pre-eclampsia, neurogenic hypertension and pulmonary hypertension [77],[78],[79]. Vascular injuries as a result of endothelial dysfunctions are linked to high- production levels of vascular ROS, OS, and vascular inflammations [80]. The ROS production in vascular smooth muscle cells (VSMC) of hypertensive patient's arteries, showed elevations of enzymatic catalytic activity of Nox. The inflammatory response of the cells in hypertensive patients enhanced by $\mathrm{O}_{2}$ - and $\mathrm{H}_{2} \mathrm{O}_{2}$, in comparison to cells from normotensive counterparts [81]. Evidence suggests that the ER stress participates in OS by a high generation of O2-, activation of the mitochondrial oxidases, and decrease in antioxidants [82],[83]. The mortality rate of newly emerged SARS CoV-2 or COVID-19 infection is associated with the patient's age and sex [84]. The data suggests the case fatality rate in adults be estimated less than $0.2 \%$ while in elderly patients above 80 reaches $9.3 \%$. The OS markers in men are generally higher than women and the levels of the ROS in postmenopausal women increases from premenopausal [54].In addition, chronic diseases like hypertension, obesity, and diabetes elevate the fatality risk by a factor of 5 times. Meanwhile, the risk is milder in younger COVID-19 patients [85].

\section{CONCLUSION}

To conclude this review, the hypothesis proposes that, rather than the obvious route of action that SARS CoV-2 dispatches to perform most of its damage, which is pneumonia in the lungs, another highly possible destination for the virus to vandalize is epithelium cells by causing OS, disturbing the environment through the generation of many ROS making a disproportion in favor of oxidants over immune function possessions of anti-oxidant mechanisms. The impact of OS is magnified if accompanied by age-related immune dysfunctions and other chronic diseases such as cardiovascular, diabetes, hypertension, and obesity. Also, antioxidants can serve as both preventatives and therapy in COVID-19 infection.

\section{REFERENCE}

[1] M. Cascella, M. Rajnik, A. Cuomo, S. C. Dulebohn, and R. Di Napoli, Features, Evaluation and Treatment Coronavirus (COVID-19). StatPearls Publishing, 2020.

[2] C. Huang et al., "Clinical features of patients infected with 2019 novel coronavirus in Wuhan, China.," Lancet (London, England), vol. 395, no. 10223, pp. 497-506, Feb. 2020, doi: 10.1016/S0140-6736(20)30183-5.

[3] M. T. Ul Qamar, S. M. Alqahtani, M. A. Alamri, and L.-L. Chen, "Structural basis of SARS-CoV-2 3CL(pro) and anti-COVID-19 drug discovery from medicinal plants.," J. Pharm. Anal., Mar. 2020, doi: 10.1016/j.jpha.2020.03.009.

[4] Y.-R. Guo et al., "The origin, transmission and clinical therapies on coronavirus disease 2019 (COVID-19) outbreak - an update on the status.," Mil. Med. Res., vol. 7, no. 1, p. 11, Mar. 2020, doi: 10.1186/s40779-02000240-0.

[5] M. Shereen, S. Khan, A. Kazmi, N. Bashir, and R. Siddique, "COVID-19 infection: Origin, transmission, and characteristics of human coronaviruses,” J. Adv. Res., vol. 24, Mar. 2020, doi: 10.1016/j.jare.2020.03.005.

[6] P. Zhou et al., "A pneumonia outbreak associated with a new coronavirus of probable bat origin.," Nature, vol. 579, no. 7798, pp. 270-273, Mar. 2020, doi: 10.1038/s41586-020-2012-7.

[7] W. Sungnak et al., "SARS-CoV-2 entry factors are highly expressed in nasal epithelial cells together with innate immune genes," Nat. Med., vol. 26, no. May, 2020, doi: 10.1038/s41591-020-0868-6. 
[8] A. B. Patel and A. Verma, "COVID-19 and Angiotensin-Converting Enzyme Inhibitors and Angiotensin Receptor Blockers: What Is the Evidence?," JAMA, Mar. 2020, doi: 10.1001/jama.2020.4812.

[9] H. Sies, "Oxidative stress: from basic research to clinical application.," Am. J. Med., vol. 91, no. 3C, pp. 31S38S, Sep. 1991, doi: 10.1016/0002-9343(91)90281-2.

[10] V. I. Lushchak, "Free radicals, reactive oxygen species, oxidative stress and its classification.," Chem. Biol. Interact., vol. 224, pp. 164-175, Dec. 2014, doi: 10.1016/j.cbi.2014.10.016.

[11] H. Sies, C. Berndt, and D. P. Jones, “Oxidative Stress.,” Annu. Rev. Biochem., vol. 86, pp. 715-748, Jun. 2017, doi: 10.1146/annurev-biochem-061516-045037.

[12] D. P. Jones, "Redefining Oxidative Stress," Antioxid. Redox Signal., vol. 8, no. 9-10, pp. 1865-1879, Sep. 2006, doi: 10.1089/ars.2006.8.1865.

[13] D. P. Jones, "Radical-free biology of oxidative stress," Am. J. Physiol. Cell Physiol., vol. 295, no. 4, pp. C849-C868, Oct. 2008, doi: 10.1152/ajpcell.00283.2008.

[14] C. P. Stanley et al., "Singlet molecular oxygen regulates vascular tone and blood pressure in inflammation.," Nature, vol. 566, no. 7745, pp. 548-552, Feb. 2019, doi: 10.1038/s41586-019-0947-3.

[15] O. A. Khomich, S. N. Kochetkov, B. Bartosch, and A. V Ivanov, "Redox Biology of Respiratory Viral Infections.," Viruses, vol. 10, no. 8, Jul. 2018, doi: 10.3390/v10080392.

[16] H. Sies, “Oxidative stress: A concept in redox biology and medicine,” Redox Biol., vol. 4, pp. 180-183, 2015, doi: 10.1016/j.redox.2015.01.002.

[17] S. P. Baba and A. Bhatnagar, "ROLE OF THIOLS IN OXIDATIVE STRESS.," Curr. Opin. Toxicol., vol. 7, pp. 133-139, Feb. 2018, doi: 10.1016/j.cotox.2018.03.005.

[18] C. L. Hawkins and M. J. Davies, "Detection, identification, and quantification of oxidative protein modifications," J. Biol. Chem., vol. 294, no. 51, pp. 19683-19708, Dec. 2019, doi: 10.1074/jbc.REV119.006217.

[19] K. K. Griendling et al., "Measurement of Reactive Oxygen Species, Reactive Nitrogen Species, and RedoxDependent Signaling in the Cardiovascular System: A Scientific Statement From the American Heart Association.," Circ. Res., vol. 119, no. 5, pp. e39-75, Aug. 2016, doi: 10.1161/RES.0000000000000110.

[20] J. J. Skoko, S. Attaran, and C. A. Neumann, "Signals Getting Crossed in the Entanglement of Redox and Phosphorylation Pathways: Phosphorylation of Peroxiredoxin Proteins Sparks Cell Signaling.," Antioxidants (Basel, Switzerland), vol. 8, no. 2, Jan. 2019, doi: 10.3390/antiox8020029.

[21] A. Casola, "Respiratory Viral Infections and Subversion of Cellular Antioxidant Defenses," J. Pharmacogenomics Pharmacoproteomics, vol. 05, no. 04, 2014, doi: 10.4172/2153-0645.1000141.

[22] Y. Higashi, K. Noma, M. Yoshizumi, and Y. Kihara, "Endothelial function and oxidative stress in cardiovascular diseases.," Circ. J., vol. 73, no. 3, pp. 411-418, Mar. 2009, doi: 10.1253/circj.cj-08-1102.

[23] F. Wu et al., "A new coronavirus associated with human respiratory disease in China.," Nature, vol. 579, no. 7798, pp. 265-269, Mar. 2020, doi: 10.1038/s41586-020-2008-3.

[24] S. Jiang, C. Hillyer, and L. Du, "Neutralizing Antibodies against SARS-CoV-2 and Other Human Coronaviruses.," Trends Immunol., vol. 41, no. 5, pp. 355-359, May 2020, doi: 10.1016/j.it.2020.03.007.

[25] A. R. Fehr and S. Perlman, "Coronaviruses: an overview of their replication and pathogenesis.," Methods Mol. Biol., vol. 1282, pp. 1-23, 2015, doi: 10.1007/978-1-4939-2438-7_1.

[26] A. C. Walls, Y.-J. Park, M. A. Tortorici, A. Wall, A. T. McGuire, and D. Veesler, "Structure, Function, and Antigenicity of the SARS-CoV-2 Spike Glycoprotein.," Cell, vol. 181, no. 2, pp. 281-292.e6, Apr. 2020, doi: 10.1016/j.cell.2020.02.058.

[27] H. Xu et al., "High expression of ACE2 receptor of 2019-nCoV on the epithelial cells of oral mucosa," Int. J. Oral Sci., vol. 12, no. 1, p. 8, 2020, doi: 10.1038/s41368-020-0074-x.

[28] L. Delgado-Roche and F. Mesta, "Oxidative Stress as Key Player in Severe Acute Respiratory Syndrome Coronavirus (SARS-CoV) infection," Arch. Med. Res., no. January, 2020, doi: https://doi.org/10.1016/j.arcmed.2020.04.019. This.

[29] G. A. Knock, "NADPH oxidase in the vasculature: Expression, regulation and signalling pathways; role in normal cardiovascular physiology and its dysregulation in hypertension.," Free Radic. Biol. Med., vol. 145, pp. 385-427, Dec. 2019, doi: 10.1016/j.freeradbiomed.2019.09.029.

[30] V. J. Dzau, "Theodore Cooper Lecture: Tissue angiotensin and pathobiology of vascular disease: a unifying hypothesis.," Hypertension (Dallas, Tex. : 1979), vol. 37, no. 4. United States, pp. 1047-1052, Apr. 2001, doi: 10.1161/01.hyp.37.4.1047.

[31] G. Zalba et al., "Vascular NADH/NADPH oxidase is involved in enhanced superoxide production in spontaneously hypertensive rats.," Hypertens. (Dallas, Tex. 1979), vol. 35, no. 5, pp. 1055-1061, May 2000, doi: 10.1161/01.hyp.35.5.1055.

[32] R. M. Touyz, "Reactive oxygen species, vascular oxidative stress, and redox signaling in hypertension: what is the clinical significance?," Hypertens. (Dallas, Tex. 1979), vol. 44, no. 3, pp. 248-252, Sep. 2004, doi: 10.1161/01.HYP.0000138070.47616.9d.

[33] A. B. Patel and A. Verma, "COVID-19 and Angiotensin-Converting Enzyme Inhibitors and Angiotensin Receptor Blockers: What Is the Evidence?,” JAMA - J. Am. Med. Assoc., 2020, doi: 10.1001/jama.2020.4812.

[34] Y. Rautureau and E. L. Schiffrin, "Endothelin in hypertension: an update.," Curr. Opin. Nephrol. Hypertens., vol. 21, no. 2, pp. 128-136, Mar. 2012, doi: 10.1097/MNH.0b013e32834f0092.

[35] R. M. Touyz et al., "Vascular smooth muscle contraction in hypertension.," Cardiovasc. Res., vol. 114, no. 4, pp. 529-539, Mar. 2018, doi: 10.1093/cvr/cvy023.

[36] R. Alves-Lopes et al., "Crosstalk Between Vascular Redox and Calcium Signaling in Hypertension Involves TRPM2 (Transient Receptor Potential Melastatin 2) Cation Channel.," Hypertens. (Dallas, Tex. 1979), vol. 75, no. 1, pp. 139-149, Jan. 2020, doi: 10.1161/HYPERTENSIONAHA.119.13861. 
[37] J. M. A. Van Den Brand, B. L. Haagmans, D. Van Riel, A. D. M. E. Osterhaus, and T. Kuiken, "ScienceDirect The Pathology and Pathogenesis of Experimental Severe Acute Respiratory Syndrome and Influenza in Animal Models *,” J. Comp. Pathol., 2014, doi: 10.1016/j.jcpa.2014.01.004.

[38] J. T. Smith, N. J. Willey, and J. T. Hancock, "Low dose ionizing radiation produces too few reactive oxygen species to directly affect antioxidant concentrations in cells," Biol. Lett., vol. 8, no. 4, pp. 594-597, Aug. 2012, doi: 10.1098/rsbl.2012.0150.

[39] C.-W. Lin, K.-H. Lin, T.-H. Hsieh, S.-Y. Shiu, and J.-Y. Li, "Severe acute respiratory syndrome coronavirus 3C-like protease-induced apoptosis.," FEMS Immunol. Med. Microbiol., vol. 46, no. 3, pp. 375-380, Apr. 2006, doi: 10.1111/j.1574-695X.2006.00045.x.

[40] K. Padhan, R. Minakshi, A. Towheed, and S. Jameel, "Severe acute respiratory syndrome coronavirus 3a protein activates the mitochondrial death pathway through p38 MAP kinase activation,” J. Gen. Virol., vol. 89, pp. 1960-1969, Aug. 2008, doi: 10.1099/vir.0.83665-0.

[41] Y. Imai et al., "Identification of oxidative stress and Toll-like receptor 4 signaling as a key pathway of acute lung injury.," Cell, vol. 133, no. 2, pp. 235-249, Apr. 2008, doi: 10.1016/j.cell.2008.02.043.

[42] H. Shao et al., "Upregulation of mitochondrial gene expression in PBMC from convalescent SARS patients," J. Clin. Immunol., vol. 26, no. 6, pp. 546-554, Nov. 2006, doi: 10.1007/s10875-006-9046-y.

[43] L. Gil del Valle, R. Gravier Hernández, L. Delgado Roche, and O. S. León Fernández, "Oxidative Stress in the Aging Process: Fundamental Aspects and New Insights," in Oxidative Stress: Diagnostics, Prevention, and Therapy Volume 2, vol. 1200, American Chemical Society, 2015, pp. 177-219 SE-6.

[44] K. J. A. Davies, "The Oxygen Paradox , oxidative stress, and ageing," Arch. Biochem. Biophys., vol. 595, pp. 28-32, 2016, doi: 10.1016/j.abb.2015.11.015

[45] S. L. Smits et al., "Exacerbated Innate Host Response to SARS-CoV in Aged Non-Human Primates," vol. 6, no. 2, 2010, doi: 10.1371/journal.ppat.1000756.

[46] P. Wenzel, S. Kossmann, T. Munzel, and A. Daiber, "Redox regulation of cardiovascular inflammation Immunomodulatory function of mitochondrial and Nox-derived reactive oxygen and nitrogen species.," Free Radic. Biol. Med., vol. 109, pp. 48-60, Aug. 2017, doi: 10.1016/j.freeradbiomed.2017.01.027.

[47] K. Y. Hood, A. C. Montezano, A. P. Harvey, M. Nilsen, M. R. MacLean, and R. M. Touyz, "Nicotinamide Adenine Dinucleotide Phosphate Oxidase-Mediated Redox Signaling and Vascular Remodeling by 16alphaHydroxyestrone in Human Pulmonary Artery Cells: Implications in Pulmonary Arterial Hypertension.,' Hypertens. (Dallas, Tex. 1979), vol. 68, no. 3, pp. 796-808, Sep. 2016, doi 10.1161/HYPERTENSIONAHA.116.07668.

[48] S. Vukelic and K. K. Griendling, "Angiotensin II, from vasoconstrictor to growth factor: a paradigm shift.," Circ. Res., vol. 114, no. 5, pp. 754-757, Feb. 2014, doi: 10.1161/CIRCRESAHA.114.303045.

[49] P. D. Ray, B.-W. Huang, and Y. Tsuji, "Reactive oxygen species (ROS) homeostasis and redox regulation in cellular signaling.," Cell. Signal., vol. 24, no. 5, pp. 981-990, May 2012, doi: 10.1016/j.cellsig.2012.01.008.

[50] A. B. Garcia-Redondo et al., "c-Src, ERK1/2 and Rho kinase mediate hydrogen peroxide-induced vascular contraction in hypertension: role of TXA2, NAD(P)H oxidase and mitochondria.," J. Hypertens., vol. 33, no. 1, pp. 77-87, Jan. 2015, doi: 10.1097/HJH.0000000000000383.

[51] Z. Wei, R. M. Salmon, P. D. Upton, N. W. Morrell, and W. Li, "Regulation of bone morphogenetic protein 9 (BMP9) by redox-dependent proteolysis.,” J. Biol. Chem., vol. 289, no. 45, pp. 31150-31159, Nov. 2014, doi: 10.1074/jbc.M1 14.579771.

[52] Y.-M. Kim, S.-J. Kim, R. Tatsunami, H. Yamamura, T. Fukai, and M. Ushio-Fukai, "ROS-induced ROS release orchestrated by Nox4, Nox2, and mitochondria in VEGF signaling and angiogenesis.," Am. J. Physiol. Cell Physiol., vol. 312, no. 6, pp. C749-C764, Jun. 2017, doi: 10.1152/ajpcell.00346.2016.

[53] R. JF, R. DG, and Y. C. LL., "Sex, oxidative stress, and hypertension: Insights from animal models.," Physiol., vol. 34, pp. 178-88, 2019.

[54] T. Ide et al., "Greater oxidative stress in healthy young men compared with premenopausal women.," Arterioscler. Thromb. Vasc. Biol., vol. 22, no. 3, pp. 438-442, Mar. 2002, doi: 10.1161/hq0302.104515.

[55] K. Bhatia, A. A. Elmarakby, A. B. El-Remessy, and J. C. Sullivan, "Oxidative stress contributes to sex differences in angiotensin II-mediated hypertension in spontaneously hypertensive rats.," Am. J. Physiol. Regul. Integr. Comp. Physiol., vol. 302, no. 2, pp. R274-82, Jan. 2012, doi: 10.1152/ajpregu.00546.2011.

[56] H. Sies, "Oxidative stress: impact in redox biology and medicine," Arch. Med. Biomed. Res., vol. 2, no. 4, p. 146, 2016, doi: 10.4314/ambr.v2i4.6.

[57] H. Sies, "Hydrogen peroxide as a central redox signaling molecule in physiological oxidative stress: Oxidative eustress.," Redox Biol., vol. 11, pp. 613-619, Apr. 2017, doi: 10.1016/j.redox.2016.12.035.

[58] A. Ore and O. A. Akinloye, "Oxidative Stress and Antioxidant Biomarkers in Clinical and Experimental Models of Non-Alcoholic Fatty Liver Disease," Medicina (Kaunas)., vol. 55, no. 2, p. 26, Jan. 2019, doi: 10.3390/medicina55020026.

[59] R. F. Furchgott and J. V Zawadzki, "The obligatory role of endothelial cells in the relaxation of arterial smooth muscle by acetylcholine.," Nature, vol. 288, no. 5789, pp. 373-376, Nov. 1980, doi: 10.1038/288373a0.

[60] L. J. Ignarro, R. E. Byrns, G. M. Buga, K. S. Wood, and G. Chaudhuri, "Pharmacological evidence that endothelium-derived relaxing factor is nitric oxide: use of pyrogallol and superoxide dismutase to study endothelium-dependent and nitric oxide-elicited vascular smooth muscle relaxation.," J. Pharmacol. Exp. Ther., vol. 244, no. 1, pp. 181-189, Jan. 1988.

[61] G. Ferrer-Sueta et al., "Biochemistry of Peroxynitrite and Protein Tyrosine Nitration.," Chem. Rev., vol. 118, no. 3, pp. 1338-1408, Feb. 2018, doi: 10.1021/acs.chemrev.7b00568.

[62] M. A. Incalza, R. D’Oria, A. Natalicchio, S. Perrini, L. Laviola, and F. Giorgino, "Oxidative stress and reactive oxygen species in endothelial dysfunction associated with cardiovascular and metabolic diseases.," 
Vascul. Pharmacol., vol. 100, pp. 1-19, Jan. 2018, doi: 10.1016/j.vph.2017.05.005.

[63] F. M. Faraci and S. P. Didion, "Vascular protection: superoxide dismutase isoforms in the vessel wall.," Arterioscler. Thromb. Vasc. Biol., vol. 24, no. 8, pp. 1367-1373, Aug. 2004, doi: 10.1161/01.ATV.0000133604.20182.cf.

[64] H. J. Forman, H. Zhang, and A. Rinna, "Glutathione: overview of its protective roles, measurement, and biosynthesis.," Mol. Aspects Med., vol. 30, no. 1-2, pp. 1-12, 2009, doi: 10.1016/j.mam.2008.08.006.

[65] J. Pizzorno, “Glutathione!," Integr. Med. (Encinitas)., vol. 13, no. 1, pp. 8-12, Feb. 2014, [Online]. Available: https://pubmed.ncbi.nlm.nih.gov/26770075.

[66] A. Polonikov, Endogenous deficiency of glutathione as the most likely cause of serious manifestations and death in patients with the novel coronavirus infection (COVID-19): a hypothesis based on literature data and own observations. 2020.

[67] Z. Varga et al., "Endothelial cell infection and endotheliitis in COVID-19," Lancet, vol. 395, no. 10234, pp. 1417-1418, 2020, doi: 10.1016/S0140-6736(20)30937-5.

[68] F. A. Klok et al., "Incidence of thrombotic complications in critically ill ICU patients with COVID-19," Thromb. Res., no. xxxx, pp. 1-3, 2020, doi: 10.1016/j.thromres.2020.04.013.

[69] N. R. Madamanchi, Z. S. Hakim, and M. S. Runge, "Oxidative stress in atherogenesis and arterial thrombosis: The disconnect between cellular studies and clinical outcomes," J. Thromb. Haemost., vol. 3, no. 2, pp. 254267, 2005, doi: 10.1111/j.1538-7836.2004.01085.x.

[70] N. R. Brady, A. Hamacher-Brady, H. V Westerhoff, and R. A. Gottlieb, "A wave of reactive oxygen species (ROS)-induced ROS release in a sea of excitable mitochondria.," Antioxid. Redox Signal., vol. 8, no. 9-10, pp. 1651-1665, 2006, doi: 10.1089/ars.2006.8.1651.

[71] D. B. Zorov, M. Juhaszova, and S. J. Sollott, "Mitochondrial ROS-induced ROS release: an update and review.," Biochim. Biophys. Acta, vol. 1757, no. 5-6, pp. 509-517, 2006, doi: 10.1016/j.bbabio.2006.04.029.

[72] E. Prompetchara, C. Ketloy, and T. Palaga, "Immune responses in COVID-19 and potential vaccines: Lessons learned from SARS and MERS epidemic,” Asian Pacific J. allergy Immunol., vol. 38, no. 1, pp. 1-9, 2020, doi: 10.12932/AP-200220-0772.

[73] G. T. Nguyen, E. R. Green, and J. Mecsas, "Neutrophils to the ROScue: Mechanisms of NADPH Oxidase Activation and Bacterial Resistance," Front. Cell. Infect. Microbiol., vol. 7, p. 373, Aug. 2017, doi: 10.3389/fcimb.2017.00373

[74] F. Lovren et al., "Angiotensin converting enzyme-2 confers endothelial protection and attenuates atherosclerosis.," Am. J. Physiol. Heart Circ. Physiol., vol. 295, no. 4, pp. H1377-84, Oct. 2008, doi: 10.1152/ajpheart.00331.2008.

[75] Y.-H. Zhang et al., "ACE2 and Ang-(1-7) protect endothelial cell function and prevent early atherosclerosis by inhibiting inflammatory response.," Inflamm. Res., vol. 64, no. 3-4, pp. 253-260, Apr. 2015, doi: 10.1007/s00011-015-0805-1.

[76] et al., "Presenting Characteristics, Comorbidities, and Outcomes Among 5700 Patients Hospitalized With COVID-19 in the New York City Area," Jama, vol. 10022, pp. 1-8, 2020, doi: 10.1001/jama.2020.6775.

[77] M. Nozoe et al., "Mitochondria-derived reactive oxygen species mediate sympathoexcitation induced by angiotensin II in the rostral ventrolateral medulla," J. Hypertens., vol. 26, no. 11, p. 2176-2184, Nov. 2008, doi: 10.1097/hjh.0b013e32830dd5d3.

[78] S. I. Dikalov and Z. Ungvari, "Role of mitochondrial oxidative stress in hypertension.," Am. J. Physiol. Heart Circ. Physiol., vol. 305, no. 10, pp. H1417-27, Nov. 2013, doi: 10.1152/ajpheart.00089.2013.

[79] V. R. Vaka et al., "Blockade of endogenous angiotensin II type I receptor agonistic autoantibody activity improves mitochondrial reactive oxygen species and hypertension in a rat model of preeclampsia.," Am. J. Physiol. Regul. Integr. Comp. Physiol., vol. 318, no. 2, pp. R256-R262, Feb. 2020, doi: 10.1152/ajpregu.00179.2019.

[80] J. Gonzalez, N. Valls, R. Brito, and R. Rodrigo, "Essential hypertension and oxidative stress: New insights.," World J. Cardiol., vol. 6, no. 6, pp. 353-366, Jun. 2014, doi: 10.4330/wjc.v6.i6.353.

[81] R. M. Touyz, G. Yao, M. T. Quinn, P. J. Pagano, and E. L. Schiffrin, "p47phox associates with the cytoskeleton through cortactin in human vascular smooth muscle cells: role in NAD(P)H oxidase regulation by angiotensin II.," Arterioscler. Thromb. Vasc. Biol., vol. 25, no. 3, pp. 512-518, Mar. 2005, doi: 10.1161/01.ATV.0000154141.66879.98.

[82] C. N. Young, "Endoplasmic reticulum stress in the pathogenesis of hypertension.," Exp. Physiol., vol. 102, no. 8, pp. 869-884, Aug. 2017, doi: 10.1113/EP086274.

[83] C. X. C. Santos, A. A. Nabeebaccus, A. M. Shah, L. L. Camargo, S. V Filho, and L. R. Lopes, "Endoplasmic reticulum stress and Nox-mediated reactive oxygen species signaling in the peripheral vasculature: potential role in hypertension.," Antioxid. Redox Signal., vol. 20, no. 1, pp. 121-134, Jan. 2014, doi: 10.1089/ars.2013.5262.

[84] A. S. Fauci, H. C. Lane, and R. R. Redfield, "Covid-19 - Navigating the Uncharted.," The New England journal of medicine, vol. 382, no. 13. United States, pp. 1268-1269, Mar. 2020, doi: 10.1056/NEJMe2002387.

[85] R. E. Jordan, P. Adab, and K. K. Cheng, "Covid-19: risk factors for severe disease and death,” BMJ, vol. 368, p. m1 198, Mar. 2020, doi: 10.1136/bmj.m1198 